\title{
Artropoda Predator Penghuni Ekosistem Persawahan di Daerah Cianjur, Jawa Barat
}

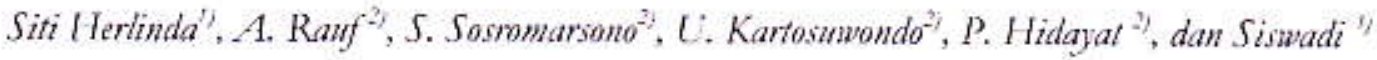 \\ ${ }_{1}^{1}$ Jurusan Hama dan Penyakit Tumbuhan, Fakultas Pertanian-Universitas Sriwijaya \\ Kampus Indralaya OKI 30662 \\ 2 Jurusan Hama dan Pencakit Tumbuhan, Fakultas Pertanian-IPB \\ Jurusan Staristik, F.IIP. -IPB
}

\begin{abstract}
Predatory arthropods inhabiting paddy rice ecosystems in Cianjur District, West Java. Predatory arthropods were surveyed in Cianjur District, West Java from July to November 1997 , with objectives to observe the species of predator arthropods inhabiting the ecosysytems. Canopy-inhabiting and soil-dwelling arthropods were sampled using D-vac and pitfall traps, respectively. Results indicated that Insecta and Arachnida were the most abundant predators in the ecosystem, with the total of 142 species. Predarory insects wcre dominared by Carabidae (27 species), and Staphylinidae (13 species) and spiders were dominated by Therididae ( 9 species), and lycosidae (8 species). Thus, predatory arthropods inhabiting the sawh ecosystems were very diverse.
\end{abstract}

Key words: Predatory arthropods, sawah ecosyrstems, Cianjur

\section{PENDAHULUAN}

Pada beberapa sentra produksi kedelai, seperti di daerah I ampung sering terjadi peledakan populasi hama penting, misalnya Etiella qinckenella dan Helicoverpa armigera (Okada el al. 1988). Fenomena yang sama sering juga terjadi pada hama padi di daerah Jalur Pantai Ltara Jawa (Pantura), seperti wereng coklat (Nilaparuta lugens) (Kenmore 1991). Namun, ekosistem persawahan di wilayah Cianjur umumnya jarang mengalami peledakan populasi hama. Kondisi seperti ini diduga ada kaitannya dengan berfungsinya agen hayati dalam menekan populasi hama tersebut. Dari hasil pengamatan awal diketahui petani di daerah Cianjur jarang atau bahkan tidak melakukan penyemprotan pestisida se- hingga memungkinkan musuh alami hidup dan berperan aktif.

Agen hayati, seperti artropoda predator telah banyak dilaporkan dapat menekan populasi hama baik pada pertanaman padi (Kenmore 1991; Hidaka 1993; Ooi and Shepard 1994; Settle et al. 1996; Tulung 2000) maupun pada pertanaman kedelai (Winasa, Taulu and Rauf 1999; Taulu et al. 2000). Misalnya, predator generalis seperti laba-laba Lycosidac dapat menekan populasi wereng coklat hingga ke tingkat yang tidak merugikan secara ekonomi (Ooi and Shepard 1994). Oleh karena itu, jenisjenis agens hayati tersebut perlu diketahui agar dapat dimanfaatkan untuk pengendalian hayati yang merupakan komponen utama Pengendalian Hama Terpadu (PHT). 


\section{BAHAN DAN METODA}

Penelitian telah dilakukan di Kecamatan Ciranjang dan Bojong picung, Kabupaten Cianjur, Jawa Barat dan dimulai bulan Juli hingga November 1997. Lokasi penelitian terletak pada ketinggian $265-330 \mathrm{~m}$ di atas permukaan laut, suhu rata-rata $27^{\circ} \mathrm{C}$, kelembaban relatif rata-rata $78,12 \%$, curah hujan ratarata $0,72 \mathrm{~mm} /$ hari. Tipe ekosistem yang dipilih untuk penelitian adalah ekosistem padi, kedelai, dan lahan bera dengan luas masing-masing lahan sckitar 3 ha. Teknik bercocok tanam padi dan kedelai mengikuti kebiasaan petani setempat tetapi ridak diperlakukan dengan pestisida sintetik.

Komunitas Predator di Pertanaman Padi. Pengamatan dilakukan mulai bulan Juli hingga November 1997. Lokasi pertanaman dipilih yang memiliki pola tanam padi-padi-padi. Pengamatan berlangsung saat padi berumur $30 \mathrm{hst}$ (hari setelah tanam), 60 hst, 90 hst dan 1 minggu setelah panen.

Pengambilan contoh artropoda penghuni tajuk menggunakan mesin pengisap serangga, D-vac. Pengambilan contoh menggunakan D-rac ini mengikuti metode Kogan and Pitre (1980), Whitcomb (1980) and McEwen (1997). Pengambilan contoh artropoda yang aktif di permukaan tanah menggunakan lubang jebakan (fitfall /rap). Pengambilan contoh menggunakan lubang jebakan mengikuti metode Price and Shepard (1980), Whitcomb (1980), Niemela,
Halme and Haila (1990) dan McEwen (1997).

Rumpun padi yang diisap artropodanya dengan $D$-vac, terlebih dahulu dikurung dengan sungkup plastik dengan kedua sisi atas (berukuran $30 \mathrm{~cm} \mathrm{x}$ $30 \mathrm{~cm}$ ) dan bawah (berukuran $40 \mathrm{~cm} \mathrm{x}$ $40 \mathrm{~cm})$ terbuka dengan ketinggian 100 $\mathrm{cm}$. Pengambilan contoh menggunakan D-vac dilakukan pada 60 rumpun (total 3 ulangan) setiap pengamatan.

Lubang jebakan dipasang di permukaan tanah dan diusahakan permukaannya rata dengan permukaan tanah di sckitarnya, lalu ditutup dengan seng berukuran $20 \mathrm{~cm} \times 20 \mathrm{~cm}$ yang dirunjang tiang kayu setinggi $15 \mathrm{~cm}$. Jumlah lubang jebakan yang dipasang adalah 60 buah (total 3 ulangan) pada setiap kali pengamatan, yang tersebar merata di pematang sawah.

Serangga dan laba-laba yang tertangkap disortasi dan dibersihkan dari kotoran. Sclanjutnya artropoda hasil sortasi tersebut disimpan dalam tabung film berisi alkohol $70 \%$ untuk diidentifikasi di laboratorium.

Komunitas Predator di Pertanaman Kedelai. Pengambilan contoh dilakukan mulai bulan Juli hingga Nopember 1997. Lokasi pertanaman dipilih yang memiliki pola tanam padipadi-kedelai. Pengamatan berlangsung saat kedelai fase $V_{3}, R_{1-2}, R_{6-7}$ dan 1 minggu setelah panen. Metode pengambilan contoh sama dengan metode di pertanaman padi gadu. Artropoda yang 
tertangkap selanjutnya diidentifikasi dan dihitung jumlah individunya.

Komunitas Predator di Lahan Bera. Pengambilan contoh dilakukan mulai bulan Juli hingga November 1997. Lokasi lahan yang dipilih memiliki pola tanam padi-padi-bera. Pengamatan berlangsung berbarengan dengan pengambilan contoh pada pertanaman padi gadu. Pengambilan contoh dengan D-vac dilakukan dengan cara mengurung dengan sungkup plastik (alas $1 \mathrm{~m} \times 1 \mathrm{~m}$, tinggi $60 \mathrm{~cm}$ ) tumbuhan liar pada permukaan tanah di lahan yang diberakan lalu diisap sebanyak 60 unit contoh (total 3 ulangan) per pengamatan. Jumlah lubang perangkap yang dipasang adalah 60 buah (total 3 ulangan) per pengamatan. Artropoda yang tertangkap selanjutnya diidentifikasi dan dihinung jumlah individunya seperti metode pengamatan di pertanaman padi gadu.

Analisis Data. Artropoda predator yang tertangkap diidentifikasi dan selanjutnya ditabulasikan. Identifikasi spesies serangga predator dan laba-laba didasarkan pada ciri morfologinya. Identifikasi serangga dilakukan di Balai Penelitian dan Pengembangan Zoologi, Puslitbang Biologi-LIPI, Cibinong, sedangkan identifikasi laba-laba dilakukan di Laboratorium Ekologi Hama, Jurusan Hama dan Penyakit Tumbuhan, Fakultas Pertanian, Institut Pertanian Bogor. Identifikasi serangga menggunakan acuan buku deGunst (1957), Kalshoven (1981), Lawrence and Britton (1994), Hadlington and Johnston (1987), Barrion and Litsinger (1990), Hilsenhoff (1991), Shepard et al. (1991), Barrion and Litsinger (1994), CSIRO (1996) dan Harde and Severa (1998). Identifikasi

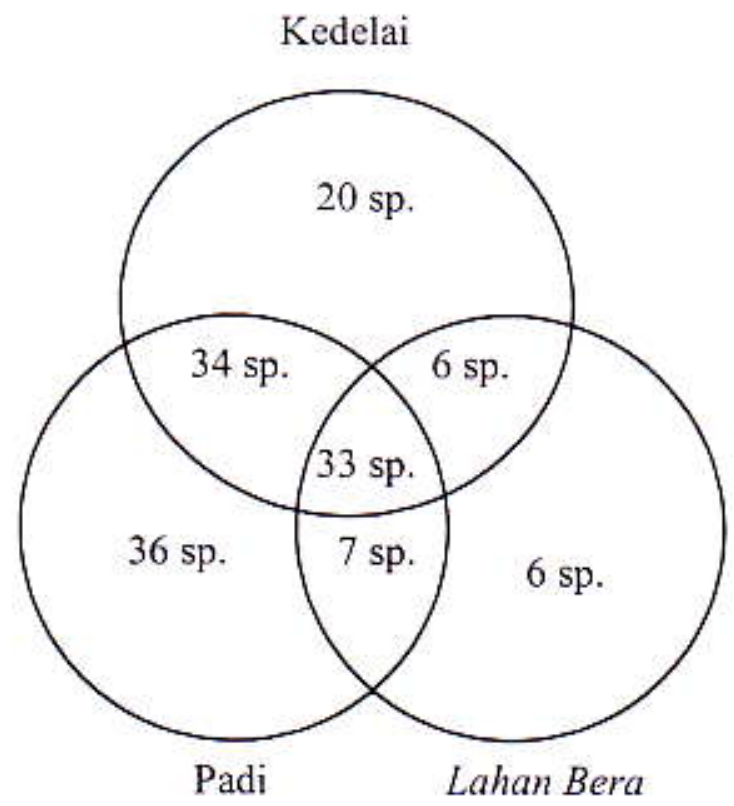

Gambar 1. Jumlah spesies artropoda predator yang terdapat di ekosistem kedelai, padi dan lahan bera yang tertangkap dengan D-vac dan lubang jebakan pada musim kemarau 1997/1998 
laba-laba menggunakan acuan buku Barrion and Litsinger (1990), Shepard $e t$ al. (1991), Barrion and Litsinger (1994) dan Barrion and Litsinger (1995).

\section{HASIL DAN PEMBAHASAN}

Pada musim kemarau tahun 1997/ 1998, jumlah total spesies artropoda predator yang tertangkap D-vac dan lubang jebakan di ekosistem persawahan (padi, kedelai, dan lahan bera) di daerah Cianjur, Jawa Barat adalah 142 spesies (Gambar 1). Pada ekosistem kedelai dan padi, jumlah spesies yang sama-sama ditemukan di kedua tempat tersebut adalah 67 spesies, sedangkan pada ckosistem padi dan lahan bera adalah 40 spesies (Gambar 1). Dari hasil ini, tampak bahwa komposisi spesies predator penghuni ekosistem kedelai dan padi lebih mirip dibanding dengan komposisi spesies predator penghuni padi dan lahan bera. Dengan demikian, relung yang terdapat di ckosistem kedelai lebih mirip dengan relung yang terdapat di ekosistem padi dibanding dengan relung yang terdapat di ekosistem lahan bera.

Jumlah total spesies artropoda predator yang tertangkap D-vac dan lubang jebakan pada ekosistem padi sebanyak 109 spesies, pada kedelai sebanyak 93 spesies dan lahan bera sebanyak 52 spesies (Gambar 1). Pada Gambar 1 tampak bahwa ada 33 spesies predator yang sama terdapat di ketiga tipe ekosistem tersebut, 36 spesies hanya ditemukan di ekosistem padi, 20 spesies hanya di ekosistem kedelai dan 6 spesies hanya terdapat di ekosistem lahan bera. Untuk 33 spesies predator yang tertangkap di ketiga tipe ekosistem in, lebih dari $60 \%$ dari jumlah semua spesies merupakan jenis predator yang aktif bergerak di permukaan tanah (Tabel 1). Predatorpredator tersebut tampaknya dapat menjelajah semua tipe ekosistem baik ekosistem yang basah seperti pematang sawah hingga ekosistem kering seperti di lahan bera. Perpindahan predator tersebut antar habitat diduga mengikuti ketersediaan mangsa pada suatu habitat. Enam spesies yang hanya ditemukan di lahan bera dan tidak ditemukan di tempat lain, yaitu 1 spesies dari Famili Miridae, 3 spesies dari Famili Reduviidae, 1 spesies dari Famili Mantidac dan 1 spesies dari Famili Lycosidae (Tabel 1). Karena predator tersebut banyak ditemukan pada siang hari, tampaknya mereka telah beradaptasi dan mampu hidup di habitat yang tak bervegetasi, kering dan panas. Spesies kumbang Famili Carabidae, yaitu Tacbys spp. merupakan spesies yang banyak ditemukan di ekosistem padi dan sangat jarang ditemukan di ekosistem kedelai serta tidak pernah ditemukan di lahan bera (Tabel 1). Dilihat dari perilakunya kumbang predator ini lebih menyukai ekosistem yang lembab terutama pada tajuk tanaman padi dan pada pernatang sawah. Spesies unik yang hanya ditemukan di ekosistem kedelai antara lain adalah Rbinocoris fusitipes (F.) (Hemiptera: Reduviidae) dan Ischidion sp. (Diptera: Syrphidae). Kalshoven (1981) melaporkan bahwa spesies pertama me- 
Tabel 1. Komposisi spesies predator yang tertangkap D-vac dan lubang jebakan pada tiga tipe ekosistem selama musim kemarau 1997/1998

\begin{tabular}{|c|c|c|c|c|}
\hline \multirow{2}{*}{ Kelas dan Ordo } & \multirow{2}{*}{ Famili dan spesies } & \multicolumn{3}{|c|}{ Tipe ekosistem } \\
\hline & & Kedelai & Padi & Bera \\
\hline \multicolumn{5}{|l|}{ INSECTA } \\
\hline \multirow[t]{46}{*}{ Coleoptera } & Anthicidae & & & \\
\hline & Anthicus sp. A & $d v, l j$ & dv,lj & dv.lj \\
\hline & Anthicus sp. B & $d v, l i$ & lj & $d v . l j$ \\
\hline & Anthicus sp. C & ji & 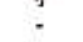 & ij \\
\hline & Formicomus sp. & $d v, l j$ & - & ? \\
\hline & $\begin{array}{l}\text { Mocynotarsus sp. } \\
\text { Cantharidae }\end{array}$ & lj & - & ij \\
\hline & Tak teridentifikasi (Cantha) & - & $d v$ & - \\
\hline & Carabidae & & & \\
\hline & Calistomimus quadricolor & - & lj & - \\
\hline & Chlaenius acroxanthus & ij & ij & ij \\
\hline & Chlaenius bimaculatus Dej. & : & $d v$ & - \\
\hline & Ch/aenius circumdatus Bruil, & ij & ij & - \\
\hline & Ch/aenius flaviguttatus Macl. & - & ij & . \\
\hline & Chlaenius hamifer & $d v$ & $:$ & - \\
\hline & Chlaenius sp & - & ij & - \\
\hline & Cicindela holosericen & ij & - & - \\
\hline & Diplocheila latifrons & ij & ij & li \\
\hline & Mastax humilis & - & ij & $:$ \\
\hline & Microlestes ater & ij & : & - \\
\hline & Poecilus sp. & ij & - & ij \\
\hline & Ophionea interstitialis (Sch.) & $d v$ & - & $:$ \\
\hline & Ophionea ishii ( $\mathrm{Hab})$. & $d v$ & $d v$ & $d v$ \\
\hline & Pheropsophus javanus (Dej.) & ij & ij & lj \\
\hline & Pheropsophus jessoensis (Mor.) & ij & ij & ij \\
\hline & Pheropsophus occipitalis (Mc.) & ij & j & ij \\
\hline & Pheropsophus sp. A. & ij & : & ij \\
\hline & Pheropsophus sp. B & ij & lj & - \\
\hline & Pheropsophus sp. C & ij & lj & - \\
\hline & Pheropsophus sp. D & ij & lj & . \\
\hline & Stenolophus smaragdufus & - & $d v$ & - \\
\hline & Tachys bombidifformis & li & dv,lj & - \\
\hline & Tachys dentatus & : & $d v$ & - \\
\hline & Tachys fasciatus & - & $d v$ & - \\
\hline & Tachys florus & - & dv & - \\
\hline & Tak teridentifikasi (Cara) & lj & $\cdot$ & - \\
\hline & Coccinellidee & & & \\
\hline & Coccinella transversalis $F$ & $d v$ & $d v$ & $d v$ \\
\hline & Coelophora inaequalis (Thunb.) & $d v$ & $d v$ & $d v$ \\
\hline & Micraspis sp & dv & $\because$ & - \\
\hline & Verania lineata Th. & $d v$ & $d v$ & $d v$ \\
\hline & Tak teridentifikasi (Cocci) & - & - & $d v$ \\
\hline & Hydrophilidae & & & \\
\hline & Tak teridentifikasi (Hydro 1) & ij & ij & - \\
\hline & Tak teridentifikasi (Hydro 2) & li & ij & - \\
\hline & Tak teridentifikasi (Hydro 3 ) & li & - & - \\
\hline & Tak teridentifikasi (Hydro 4) & - & lj & ij \\
\hline
\end{tabular}

rupakan predator bagi hama penting kedelai, yaitu Spodoptera spp. (Lepidoptera: Noctuidae) dan H. armigera (Lepidoptera: Noctuidac). Spesies kedua merupakan predator penting pada kutu daun yang banyak menyerang tanaman kedelai di musim kemarau. Dengan demikian, keberadaan kedua spesies predator tersebut di ekosistem kedelai terkait dengan spesies hama tertentu yang banyak ditemukan di ekosistem kedelai. 
Tabel 1. Lanjutan

\begin{tabular}{|c|c|c|c|c|}
\hline \multirow{2}{*}{ Kelas dan Ordo } & \multirow{2}{*}{ Famili dan spesies } & \multicolumn{3}{|c|}{ Tipe ekosistem } \\
\hline & & Kedelai & Padi & Bera \\
\hline & Pselaphidae & & & \\
\hline & Euplectus sp. A & lj & - & - \\
\hline & $\begin{array}{l}\text { Euplectus Sp. B } \\
\text { Staphylinidae }\end{array}$ & ij & i5 & - \\
\hline & Astenus sp. & lj & $d v, \mathrm{lj}$ & - \\
\hline & Atanygnatus sp. & $d v$ & - & - \\
\hline & Criptobium abdominale & $d v$ & $d v$ & - \\
\hline & Hydrosmecta sp. & - & jj & ij \\
\hline & Leptacinus sp. & - & $d v$ & . \\
\hline & Myllaena sp. & ij & $d v, \mathrm{lj}$ & - \\
\hline & Ocalea sp. & - & $d v, \mathrm{Ij}$ & . \\
\hline & Paederus fuscipes Curt. & dv,lj & $d v, i j$ & $d v, l j$ \\
\hline & Paederus tamulus Erich. & $d v, l j$ & $d v$ & . \\
\hline & Paederus sp & $d v$ & - & - \\
\hline & Scopaeus sp & $d v$ & $d v$ & - \\
\hline & Stenus sp. & - & dv & . \\
\hline & Trogophloeus sp & - & $d v$ & - \\
\hline \multirow[t]{3}{*}{ Dermaptera } & Labiidae & & & \\
\hline & Labia sp. & ij & $d v ., j$ & $d v$ \\
\hline & Chaetospania Sp. & ij & it & - \\
\hline \multirow[t]{4}{*}{ Diptera } & Dolichopodidae & & & \\
\hline & Tak teridentifikasi (Doli) & $d v, l j$ & $d v, I j$ & - \\
\hline & Sytphidae & & & \\
\hline & Ischidion sp. & $d v, j$ & - & . \\
\hline \multirow[t]{27}{*}{ Hemiptera } & Corixidae & & & \\
\hline & $\begin{array}{l}\text { Micronecta sp. } \\
\text { Gerridae }\end{array}$ & - & dv & - \\
\hline & Hydrometra sp. & if & - & - \\
\hline & Mesoveliidae & & & \\
\hline & Mesovefia vittigera & $d v$ & dv & If \\
\hline & Miridae & & & \\
\hline & Cyrtorhinus lividipennis Reut. & $d v$ & dv & - \\
\hline & Tak teridentifikasi (Mirid 1) & $d v, l j$ & lj & - \\
\hline & Tak teridentifikasi (Mirid 2) & $d v$ & - & - \\
\hline & Tak teridentifikasi (Mirid 3) & $d v, j$ & - & - \\
\hline & Tak teridentifikasi (Mirid 4) & - & - & $d v, i j$ \\
\hline & Tak teridentifikasi (Mirid 5) & ij & $d v$ & $d v$ \\
\hline & Pentatomidae & & & \\
\hline & Andralius spinidens ( $F)$. & $d v$ & $d v .1 j$ & - \\
\hline & Reduvidae & & & \\
\hline & Coranus sp. & $d v$ & $d v$ & - \\
\hline & Lisarda Sp. & - & - & $d v$ \\
\hline & Oncocephalus sp. & - & - & if \\
\hline & Rhinocoris fuscipes (F.) & $d v$ & - & - \\
\hline & Sirtheanea sp. & . & lj & - \\
\hline & Sycanus annulicornis Dohrn & - & $d v$ & - \\
\hline & Tak teridentifikasi (Reduv 1) & $d v$ & $d v$ & $d v$ \\
\hline & Tak teridentifikasi (Reduv 2) & - & $d v$ & - \\
\hline & Tak teridentifikasi (Reduv 3) & - & $d v$ & . \\
\hline & Tak teridentifikasi (Reduv 4) & $d v$ & - & - \\
\hline & Tak teridentifikasi (Reduv 5) & - & - & $d v$ \\
\hline & Tak teridentifikasi (Reduv 6 ) & $d v, l j$ & $d v$ & $d v$ \\
\hline
\end{tabular}

Dari 142 spesies artropoda yang ditemukan tersebut, $71,83 \%$ (102 spesies) di antaranya adalah serangga predator (Tabel 1) dan 28,17\% (40 spesies) adalah laba-laba (Tabel 1). Artropoda predator yang tertangkap lubang jebakan terbanyak adalah artropoda predator penghuni tanah seperti kumbang pre- 
Tabel 1. Lanjutan

\begin{tabular}{|c|c|c|c|c|}
\hline \multirow{2}{*}{ Kelas dan Ordo } & \multirow{2}{*}{ Famili dan spesies } & \multicolumn{3}{|c|}{ Tipe ekosistem } \\
\hline & & Kedelai & Padi & Bera \\
\hline & Veliidae & & & \\
\hline & Microvelia sp. & jo & $d v$ & - \\
\hline \multirow[t]{14}{*}{ Hymenoptera } & Formicidae & & & \\
\hline & Anoplolepis sp. & - & $d v, i j$ & リ \\
\hline & Camponotus $s p$ & - & $d v, l i j$ & ij \\
\hline & Dolichoderus sp. A & lj & lj & if \\
\hline & Dolichoderus sp. B & ij & j & if \\
\hline & Dorylus sp. & - & ij & - \\
\hline & Leptagenys sp. & - & $\hat{i j}$ & ij \\
\hline & Myrma sp. & lj & dv & $d v, j$ \\
\hline & Odontoponera sp. & dv,li & dv,lj & $\cdot$ \\
\hline & Oecophyla sp. & $d v$ & $d v, l j$ & $\cdot$ \\
\hline & Paratrechina sp. A & dv, li & dv,ij & $d v, \mathrm{lj}$ \\
\hline & Paratrechina sp. B & lj & Ij & ij \\
\hline & Solenopsis gemminata (Fabr.) & $d v, j$ & dvili & $d v, l j$ \\
\hline & Tak teridentifikasi (Formi) & if & - & - \\
\hline \multirow[t]{9}{*}{ Odonata } & Coenagrionidae & & & \\
\hline & Tak teridentifikasi (Coena) & - & $d v$ & - \\
\hline & Gryllidae & & & \\
\hline & Anaxipha Sp. & dv & $d v$ & - \\
\hline & Metioche sp. & dv,lj & $d v, j$ & * \\
\hline & Mantidae & & & \\
\hline & Tak teridentifikasi (Manti) & - & - & $d v$ \\
\hline & Tettigonidae & & & \\
\hline & Conocephafus sp. & $d v, i j$ & dv & dv \\
\hline \multicolumn{5}{|l|}{ ARACHNIDA } \\
\hline \multirow[t]{16}{*}{ Araneae } & Araneidae & & & \\
\hline & Araneus inustus Koch & $d v$ & $d v$ & - \\
\hline & Argiope catenulata (Dol.) & - & - & - \\
\hline & Clubionidae & & & \\
\hline & Alachosp. & $d v, i f$ & - & - \\
\hline & Castianeira tiranglupa Bar. and Lit. & If & ij & - \\
\hline & Clubiona japonicola Boes. and Str. & $d v$ & $d v$ & - \\
\hline & $\begin{array}{l}\text { Phrurolithus uiopatulisus Bar, and Lit. } \\
\text { Lycosidae }\end{array}$ & $\cdot$ & lj & - \\
\hline & Arctosa tanakai Koch & $d v, j$ & dv.li & I) \\
\hline & Hipassa hoimerae Th. & li & dv,ij & : \\
\hline & Pardosa birmanica Sim. & dvilj & $d v, i j$ & jj \\
\hline & Pardosa pahalanga Bar. and Lit. & - & $d v$ & - \\
\hline & Pardosa pseudoannulata (Boes. and Str.) & dv.lj & $d v, l j$ & dv, lif \\
\hline & Pirata blabakensis Bar. and Lit. & Ij & - & ij \\
\hline & Trochosa canapi Bar, and Lit. & $\therefore$ & $\cdot$ & i \\
\hline & Venonia sp & - & Ij & - \\
\hline
\end{tabular}

dator Famili Carabidac dan laba-laba pemburu Famili Lycosidae (Tabel 1). Pengamatan dengan lubang jebakan terbatas pada artropoda yang aktif bergerak di permukaan tanah (Southwood 1980). Pengamatan dengan D-vac menunjukkan jumlah spesies artropoda predator penghuni tajuk seperti kepik predator lebih banyak terkumpul dibandingkan spesies artropoda predator penghuni ta- nah (Tabel 1). Dengan demikian, peng. amatan menggunakan D-vac lebih sesuai untuk penghuni tajuk daripada penghuni tanah. 
Tabel 1. Lanjutan

\begin{tabular}{|c|c|c|c|c|}
\hline \multirow{2}{*}{ Kelas dan Ordo } & \multirow{2}{*}{ Famili dan spesies } & \multicolumn{3}{|c|}{ Tipe ekosistem } \\
\hline & & Kedelai & Padi & Bera \\
\hline \multicolumn{5}{|c|}{ Lyniphiidae } \\
\hline & Atypena adelinae Bar. and Lit. & dv,lij & $d v, l j$ & lj \\
\hline & Bathyphantes tagalogensis Bar. and Lit. & $d v, l j$ & $d v, l j$ & : \\
\hline & Erigone bifurca Lock. & $d v, \mathrm{lj}$ & $\mathrm{dv}, \mathrm{lj}$ & - \\
\hline \multicolumn{5}{|c|}{ Oonopidae } \\
\hline & $\begin{array}{l}\text { Opopaea batanguena Bar.and Lit. } \\
\text { Oxyopidae }\end{array}$ & - & $d v, i j$ & $\cdot$ \\
\hline & Oxyopes javanus Th. & $d v, l j$ & $d v$ & $d v$ \\
\hline & Oxyopes lineatipes Koch & - & $d v$ & - \\
\hline \multicolumn{5}{|c|}{ Salticidae } \\
\hline & Bianor sp. & $d v$ & $d v$ & dv,lij \\
\hline & Harmochirus brachiatus (Th.) & $d v$ & $d v$ & $d v$ \\
\hline & Myrmarachne markaha Bar. and Lit. & $\cdot$ & $d v$ & $\cdot$ \\
\hline & Plexippus sp & - & $d v$ & - \\
\hline \multicolumn{5}{|c|}{ Tetragnathidae } \\
\hline & Dyschiriognatha hawigtenera Bar. and Lit. & $d v$ & $d v, 1 j$ & - \\
\hline & Tetragnatha javana (Th.) & $d v$ & $d v$ & - \\
\hline & Tetragnatha maxillosa $\mathrm{Th}$. & - & dv & - \\
\hline & Tetragnatha nitens (Aud.) & - & $d v$ & $\cdot$ \\
\hline & Tetragnatha vermiformis Em. & - & $d v$ & - \\
\hline & Tak teridentifikasi (Tetra) & . & dv & . \\
\hline \multicolumn{5}{|c|}{ Theridiidae } \\
\hline & Anelosimus nigrobaricus Bar. and Lit. & it & $d v, i j$ & Ij \\
\hline & Anelosimus salaensis Bar, and Lit. & - & $d v, i j$ & أj \\
\hline & Coleosoma blandum Cam. & $d v, l i$ & ij & ij \\
\hline & Coleosoma caliothripsum Bar. and Lit. & $d v$ & - & - \\
\hline & Coleosoma saispotum Bar, and Lit. & - & ij & - \\
\hline & Dipoena tuldokguhitanea Bar. and Lit. & - & dv & - \\
\hline & Enoplognatha sp. & - & if & - \\
\hline & Landoppo sp. & lj & ij & lj \\
\hline & $\begin{array}{l}\text { Theridion otsospotum Bar. and Lit. } \\
\text { Thomisidae }\end{array}$ & $d v$ & dv & - \\
\hline & Runcinia albostriata Boes. and Str. & - & $d v$ & . \\
\hline
\end{tabular}

Keterangan: Predator terkumpul dengan D-vac (dv), lubang jebakan (j) dan tidak ditemukan ( - )

\section{KESIMPULAN}

Artropoda predator yang umum ditemukan adalah dari kelas Insecta dan Arachrida dengan total jumlah spesies 142. Dari kelas Insecta, spesies yang paling banyak ditemukan adalah spesies dari famili Carabidae (27 spesies) dan Staphylinidae (13 spesies), sedangkan dari kelas Arachnida, spesies yang paling banyak ditemukan adalah spesies dari famili Theridiidae ( 9 spesies) dan Lycosidae (8 spesies). Dengan demikian, artropoda predator di ekosistem persawahan cukup kompleks dan beranekaragam. Kompleks dan beranekaragam- nya agen hayati tersebut sangat penting guna dimanfatkan dan dikembangkan dalam mengendalikan hama secara hayati.

\section{PUSTAKA}

Barrion, A.T and J.A. Litsinger. 1990. Taxonomy of Rice Insed Pests and Their Arthropod Parasites and Predators. International Rice Research Institute. Philippines. $580 \mathrm{p}$.

Barrion, A.T. and J.A. Litsinger. 1994. Taxonony of Rive Insect Pests and Their Arthmopod Parasites and Predators, p. 13-362. In E.A. Heinrichs (Ed.). Biolog and Management of Rice Insets. Wiley Eastern Limited. New Delhi.

Barrion, A.T. and J.A. Lirsinger. 1995. Riceland Spiders of Soutb and Southeast Aisa. 
International Rice Research Institute. Philippines, $716 \mathrm{p}$.

CSIRO (Commonwealth Scientific and Industrial Reseaarch Organization). 1996. The Insects of Asstralia: A Textbook for studen/s and Researly Workers. Second Edition. Melbourne Universiry Press. Victoria. $1137 \mathrm{p}$.

deGunst, J.H. 1957. Indonesia Ladr-birds. Pergecmar Alam. 36(3):3-17.

Hadlington, P. .W. and J.A. Johnston. 1987. An Introduction to Ausitralian lnstets. South China Co. Hongkong. $116 \mathrm{p}$.

Harde, K.I. and F. Severa 1998. A Freld Gate in Colar to Beetles. Aventinum Publishing House. Ceech Republic, 333 p.

Hidaka, K. 1993. Farming ststems for rice cultivation which promote the regulation of pest populations by natural enemies: Planthopper management in radirional, intensive farming and LIS. I rice cultuvation in Japan. Ext. Bull. 374:1-15.

Hilsenhoff, W.L. 1991. Diversin and classification of insects and Collembolla, $\mathrm{p}$. 593-664. In J.H. Thorp and A.P. Covich (cds.). Ecology and Classiftiation of North Amsina Freshwater Inwertebrates. Academic Press, Inc. San Diego.

Kalshoven, I.G.F. 1981. Pests of Crops it Indontisia. Revised and Translated by van der Laan. PT Ichtiar Baru - van Hoeve. Jakarta. $701 \mathrm{p}$.

Kenmore, P.E. 1991. Getting policies right, keeping policies right: Indonesia's IPXI policy, production, and environtment. Dalam ARPE Environment and Agriculture Officer's Conference 11 September 1991, Colombo, Srilanka. 51 p,

Kogan, M. and H.N. Pitre. 1980. General sampling methods for above-ground populations of soybcan arthropods, p. 30 . 60. In . . Kogan and D.C. Herzog (eds.). Sanplinglethads in Sobtan Entomolog: Springer-verlag. New lork.

Lawrence, J.F. and E.B. Britton. 1994. Arstralion Buthes. Melbourne Lniversity Press. Victoria. $192 \mathrm{p}$.

AcEwen, P. 1997. Sampling, handling and rearing insects, p. 5-26. In D.R. Dent and M.P. Walton (eds.). Methods in Esological and Agrin/tual Entomolog: Lniversity Press. Cambridge.
Niemela, J.X., E. I lalme and Y: Haila. 1990. Balancing sampling effort in pitfall trapping of carabid beetles. Entomol Fenmia. 1:233-238.

Okada, T., J. Soejitno, M.S. Pabbage and W. Tengkano. 1988, Jenis dan penuebaran penggerek polong dan pemakan polong kedelai di Indonesia. Seminar Balitian Bogor. 6 Desember 1988, $27 \mathrm{~h}$.

Ooi, P.A.C. and B.M. Shepard. 1994. Prectators and parasitoids of rice insect pesers, p. 585 612. In E.t. Heinrichs (Ed.). Biolog and Management of Rice lnsects. Wiley Fastern Limited. New Delhi.

Price, J.F. and B.M. Shepard. 1980. Sampling groud predators in soybean ficlds, p. 530 ) 543. In . . Kogan and D.C. Herzog (Edi.), Sampling Methods in Soyuran Enomolog. Springer verlag. New York.

Settle, W.H., H. Ariawan, E.T. Asrum, W. Cahyana, A.L. Hakim, D. Hindayana, A. S. l.estari and Pajarningsih. 1996. Managing tropical rice pest through conservation of generalist natural cnemies and altcrnative prey. Evolog: $77(7): 1975-1988$.

Shepard, B.M., A.T. Barrion and J.A. Litsinger. 1987. Friend of the Rio larmer: Hoblut Insetts, Spiders, and Pathogens. International Rice Research Institute. Philippines. $136 \mathrm{p}$.

Taulu, L.A., A. Rauf, S. Sosromarsono, F. Rumawas, H. Truidodo and E.S. Ratma. 2000. Perkembangan populasi dan peranan Paederus fnocipes (Colcopteta: Staphylinudac) di pertanaman kedelas. Seminar Pps, JPB, 8 Juni $2000.17 \mathrm{~h}$.

Tulung, M. 1999. Ekologi Laba-laba de Pertanamat Padi dengan Periatian Ciama pada Pardora psendoannulata (Bots. and Str., Pps, IPB. 120 h. (Disertasi).

Whitcomb, W.H, 1980. Sampling spiders in soybean ficlds, p. 544-548. In XI. Kogan and D.C. Herzog (cds.). Sampling Methods in Soybean Entomolog. Springer-verlag. New York.

Winasa, I.W. , L. Taulu and A. Rauf. 1999. Kaijan peran predator penghuni tanah dan tajuk di ekosistem kedelai. Prosiding Seminar Timu Teknologi Hasil Penelitian Pendukusg PHT, Cisarua 27.30 Juni 1999. $1.3 \mathrm{~h}$. 